\title{
Bonds and Bridges: The Role of Social Capital in Building a More Diverse Dermatology Workforce
}

\author{
Qaren Q. Quartey, BA; Rachel O. Edoror, BS; Angel S. Byrd, MD, PhD; Ginette A. Okoye, MD
}

\section{PRACTICE POINTS}

- Achieving diversity in the field of dermatology will require a concerted effort to equalize access to mentorship, information, exposure, and networking for students of all backgrounds.

- Valuing diverse forms of capital in applicants ultimately will strengthen the dermatology workforce through inclusion of various lived experiences and perspectives.
Several calls to action have been made in response to the lack of racial diversity in dermatology, but we have yet to explore how differences in social capital perpetuate homogeneity in dermatology training programs and the workforce. Herein, the concept of social capital is applied to this problem in dermatology and is used as a scaffold to suggest interventions that may ameliorate the systemic barriers faced by underrepresented-in-medicine (UIM) students.

Cutis. 2020;106:242-244.

$\bigwedge$ s our specialty seeks to address its lack of racial diversity, many dermatologists have answered recent calls to action. ${ }^{1,2}$ As we work toward dismantling systemic issues that have created pervasive inequality in our residency application review and interview processes, consideration also should be given to psychosocial issues that underrepresented-in-medicine (UIM) students face before their applications come to our attention. In this article, we explore how potential differences in the social capital of UIM and other disadvantaged dermatology residency applicants contribute to persistent homogeneity among dermatology training programs and the workforce.

\section{The Theory of Capital}

The concepts of economic, social, and cultural capital originate from the writings of social theorist Pierre Bourdieu. ${ }^{3}$ All 3 forms of capital are interconnected, and they relate to each other in ways that often facilitate social division and inequality. Economic capital denotes an individual's economic resources or wealth, while cultural capital refers to the knowledge, behaviors, and skills that demonstrate his/her economic class (eg, communication style, table manners). ${ }^{3}$ Social capital refers to an individual's interpersonal connections in personal and professional settings and can be subdivided into 3 categories: bonds, bridges, and linkages. ${ }^{4,5}$ Herein, we will focus on bonds and bridges.

It has been suggested that bonds are important for "getting by,"while bridges are critical for" getting ahead." Bonds refer to close relationships within a community of people with shared characteristics, such as racial/ethnic identity and culture, access to information, and resources (eg, family, friends). These bonds provide trust, safety, and financial and emotional support; however, they are considered to be inward-looking and can promote exclusion and homogeneity. ${ }^{5}$

Ms. Quartey and Ms. Edoror are from the University of Maryland School of Medicine, Baltimore. Drs. Byrd and Okoye are from the Department of Dermatology, Howard University, Washington, DC.

The authors report no conflict of interest.

Correspondence: Ginette A. Okoye, MD (Ginette.okoye@howard.edu).

doi:10.12788/cutis.0111 
On the other hand, bridges refer to social relationships that extend outward beyond one's close circle of family and friends to other people with shared interests and goals who may have different social or cultural identities (eg, professional colleagues). These bridges are considered to be outward-looking and provide many benefits to individuals and society. They link diverse individuals, which tends to increase tolerance and disrupt stereotypes, and they facilitate the sharing of ideas, information, and innovation. Additionally, bridges between individuals from different networks facilitate access to increased resources and opportunities for all parties. ${ }^{5}$

The 3 forms of capital are inextricably linked. For example, with economic capital, a child's family can purchase access to a prestigious private high school, where he/she will gain valuable social capital through bridges with other students and their families. At this school, the child also will accumulate cultural capital that increases his/her sense of belonging in these circles. Subsequently, both the social and cultural capital accumulated at this private high school can be exchanged for economic capital via social networks, skills, values, and behaviors that facilitate entry into higher education and professional training. As such, these 3 forms of capital work together to continue social/class divisions, hierarchies, and ultimately inequality.

\section{Impact of Social Capital in Pursuing a Medical Career}

For medical students whose bonds (ie, close family, friends) include physicians or other health care professionals, the journey to studying medicine and entering their chosen specialty will be facilitated by financial security, valuable "inside information" about the application process, study skills, and even clinical guidance. Additionally, these students will have access to professional networks for mentorship, shadowing experiences, and other potential adyantages. Furthermore, social capital is associated with higher self-esteem, ${ }^{6}$ which likely improves academic performance and wards off imposter syndrome in these students.

For medical students from lower socioeconomic status backgrounds or those whose inner circles do not include physicians or other health care professionals, accumulating the social and cultural capital needed to successfully navigate a medical career is more difficult. Although they may receive support and encouragement from family and friends, they will not have access to the same valuable information and connections that facilitate success; rather, they will have a further distance to travel, and this distance should be acknowledged in the residency application review process.

\section{Acquiring Social Capital as a UIM Student}

Despite the benefits of social and cultural capital, acquiring them takes a toll. For those UIM students who start life from a disadvantaged place, the accumulation of social capital does not come easily; rather, it demands effort and time that has the potential to detract from a student's focus on the academic demands of medical education. ${ }^{7}$ Programs that attempt to improve disadvantaged students' access to credible information, role models, and mentors can help lift some of the burden from the individual student's shoulders. For example, studies have demonstrated the benefits of harnessing technology to enhance mentorship programs that increase social capital of disadvantaged populations. ${ }^{8-11}$ This approach already is in progress, bolstered by advances made in digital communications during the coronavirus disease 2019 pandemic. ${ }^{12}$ Student-led networking groups that connect remotely have been shown to build social capital bonds and bridges that facilitate collaborative learning, relationship building, and information sharing. ${ }^{8-11}$ There are existing online UIM student networks that individual dermatologists, institutions, and national organizations can partner with to facilitate the construction of bridges between these UIM student groups and dermatologists who can provide accurate, high-yield information and professional networking; however, one limitation of this suggestion is the disparate access to technology in the UIM community.

\section{Final Thoughts}

It is important to note that assumptions should not be made about the level of economic, social, or cultural capital an individual possesses based on his/her race or ethnicity. Instead, mentors should attempt to be available to a diverse pool of students; take the time to get to know these students; and then provide the types of mentorship, information, exposure, and networking that each individual student needs. Another approach is to make a concerted effort to ensure that all students receive the same amount and quality of information about medical education and our specialty regardless of their level of economic, cultural, or social capital. Moreover, beyond the promotion of diversity through increasing numbers of UIM applicants, we should seek to reshape our specialty into a space that does not require students to subdue their existing diverse forms of capital but rather to bring these different perspectives and lived experiences to the table. ${ }^{13}$

\section{REFERENCES}

1. Bray JK, McMichael AJ, Huang WW, et al. Publication rates on the topic of racial and ethnic diversity in dermatology versus other specialties. Dermatol Online J. 2020;26:7.

2. Pritchett EN, Pandya AG, Ferguson NN, et al. Diversity in dermatology: roadmap for improvement. J Am Acad Dermatol. 2018;79:337-341.

3. Bourdieu P. The forms of capital. In: Richardson J, ed. Handbook of Theory and Research for the Sociology of Education. Westport, CT: Greenwood; 1986:241-258.

4. Granovetter MS. The strength of weak ties. Am J Sociol. 1973; 78:1360-1380.

5. Putnam RD. Bowling alone: America's declining social capital. J Democracy. 1995;6:65-78. 
6. Han S. Longitudinal association between social capital and selfesteem: a matter of context. Psychiatry Research. 2015;226:340-346.

7. Kirschling JM. Building social capital: leading and leveraging constituencies outside the college. J Nurs Educ. 2004;43:517-519.

8. Radlick RL, Svedberg P, Nygren JM, et al. Digitally enhanced mentoring for immigrant youth social capital: protocol for a mixed methods pilot study and a randomized controlled trial [published online March 17, 2020]. JMIR Research Protocols. doi:10.2196/16472.

9. Koh LC, Walker R, Wollersheim D, et al. I think someone is walking with me: the use of mobile phone for social capital development among women in four refugee communities. Int J Migration Health Social Care. 2018;14:411-424.
10. Hartley A, Kassam AA. Social networking for learning in higher education: capitalising on social capital. ResearchGate website. https://www.researchgate.net/publication/311097860_Social _Networking_for_Learning_in_Higher_Education_Capitalising_on _Social_Capital. Published November 2016. Accessed October 19, 2020.

11. Zalon ML. Using technology to build community in professional associations. J Contin Educ Nurs. 2008;39:235-240.

12. Stewart CR, Chernoff KA, Wildman HF, et al. Recommendations for medical student preparedness and equity for dermatology residency applications during the COVID-19 pandemic. J Am Acad Dermatol. 2020;83:E225-E226.

13. Brosnan C, Southgate E, Outram S, et al. Experiences of medical students who are first in family to attend university. Med Educ. 2016;50:842-851. 